\title{
Retargeting improves the efficacy of a telomerase-dependent oncolytic adenovirus for head and neck cancer
}

\author{
RAINE TOIVONEN $^{1-3}$, ELINA SUOMINEN ${ }^{1,2}$, REIDAR GRENMAN $^{2,4}$ and MIKKO SAVONTAUS ${ }^{1,2,5}$ \\ ${ }^{1}$ Turku Centre for Biotechnology, Åbo Academy and University of Turku; ${ }^{2}$ Department of Medical \\ Biochemistry and Molecular Biology, University of Turku; ${ }^{3}$ Turku Graduate School of Biomedical \\ Sciences, Åbo Academy and University of Turku; ${ }^{4}$ Department of Otorhinolaryngology - Head \\ and Neck Surgery, ${ }^{5}$ Department of Medicine, University of Turku, Turku, Finland
}

Received August 4, 2008; Accepted September 10, 2008

DOI: $10.3892 /$ or_00000204

\begin{abstract}
The relative paucity of receptors for the commonly used adenovirus serotype 5 in many cancer types undermines the efficacy of Ad5-based approach for cancer gene therapy. We have previously shown that coxsackie-adenovirus receptor (CAR) is expressed at decreased levels in several primary head and neck squamous cell carcinoma (HNSCC) cell lines established from tumor samples and that retargeting adenoviral infection to the CD46 receptor using the Ad5/35 hybrid virus results in highly efficient transfection of these cells. We sought to examine the effect of this retargeting in the context of the conditionally replicating adenovirus (CRAD) approach. By subjecting the viral E1A gene under the regulation of human telomerase reverse transcriptase promoter we produced Ad5/35-TERT, a transductionally targeted CRAD. The anti-tumor efficacy of this virus was tested in two primary HNSCC cell lines, chosen to represent high $(55.2 \%)$ and low $(3.2 \%)$ CAR expression levels. In vitro experiments demonstrated that Ad5/35-TERT is significantly more effective in killing primary HNSCC cells than the non-targeted Ad5-TERT. The difference between the two viruses was clearly more pronounced in HNSCC cells with low CAR expression. In an in vivo experiment using a subcutaneous HNSCC mouse model Ad5/35-TERT was more effective than Ad5-TERT in both high- and low-CAR HNSCC cells. These results demonstrate that enhanced transfection by hybrid virus strategy results in an increased anti-tumor efficacy when using CRADs. The effect is especially distinctive in target cells with low CAR expression.
\end{abstract}

Correspondence to: Dr Mikko Savontaus, Turku Centre for Biotechnology, University of Turku, Tykistökatu 6B, 5th floor, FIN-20520, Turku, Finland

E-mail: mikko.savontaus@btk.fi

Key words: telomerase, adenovirus, head and neck cancer

\section{Introduction}

Serotype 5 adenoviruses are currently the most widely used vectors in clinical cancer gene therapy trials. They attach to target cells via a specific interaction between the viral fiber knob domain and the coxsackie and adenovirus receptor (CAR) (1-3). Attached viruses are internalized by an interaction between the capsid penton base protein and cellular $\alpha_{v} \beta_{3}$ and $\alpha_{v} \beta_{5}$ integrins (4). Despite the fact that adenoviral vectors possess many favorable in vivo gene delivery characteristics, including a broad spectrum of infectivity of both resting and proliferating cells, adenovirusmediated gene transfer to many important gene therapy targets, such as primary tumor cells is inefficient. In many cases this has been shown to be caused by low expression levels of CAR on target cells $(5,6)$. Redirecting adenoviral vectors to other, preferentially target-specific cellular receptors and abolishing the natural interaction between viral capsid proteins and their cellular counterparts has thus become a major goal in gene therapy.

Several strategies have been employed to transductionally target the adenovirus, including the use of bivalent targeting complexes and engineering genetic alterations to viral capsid proteins (7-10). Another approach is to use hybrid adenoviruses in which the fiber gene from one serotype has been swapped to that of another. Native adenoviruses have different tissue tropisms, indicating that hybrid adenoviruses have the potential of becoming useful retargeting tools. Serotype 35 adenovirus, a member of group B adenoviruses, uses CD46 as a primary cellular receptor and thus infects cells in a CARindependent manner (11). CD46 is a membrane protein with a ubiquitous expression pattern in humans (12). Extensive data demonstrate that Ad35 or hybrid Ad5/35 is able to efficiently transduce many human cell types that are relatively resistant to Ad5 infection, including $\mathrm{CD} 34^{+}$cells, tumor endothelial cells and cervical, breast and colon cancer cells (13-16). In addition, we have recently demonstrated that Ad5/35 infects primary HNSCC cells with high efficiency (17).

Replication-selective oncolytic viruses provide a promising strategy to cancer treatment, as they are able to replicate in tumor cells and spread to neighboring tumor cells upon cell 
lysis. CRADs can be produced either by deleting adenovirus genes that are necessary for viral replication only in nonmalignant cells or by utilizing tumor- or tissue-specific promoters to drive viral replication (18). Telomerase, a DNA polymerase directing the synthesis of telomeres is an attractive target for tumor-specific targeting as telomerase becomes dormant in post-mitotic tissues soon after birth but become highly active in most human malignancies. Telomerase activation is considered to be a critical step in carcinogenesis and its activity correlates closely with human telomerase reverse transcriptase (hTERT) expression (19-21). Based on this paradigm the telomerase reverse transcriptase (TERT) promoter has previously been utilized to produce serotype 5 CRADs, which have demonstrated efficacy in various tumor models (22-25).

Head and neck squamous cell carcinoma (HNSCC) has been considered one of the most promising targets for CRAD therapy as loco-regional control of this disease is paramount even in advanced cases and HNSCC tumors are often relatively easily accessible by intratumoral injection (26-28). In this study we sought to analyze the effects of transductional retargeting and CAR expression in HNSCC cells on the anti-tumor efficacy of CRADs. To this end, we compared the efficacy of Ad5/35-TERT, a transductionally targeted CRAD against a non-targeted CRAD Ad5-TERT in HNSCC cells with either high or low CAR expression.

\section{Materials and methods}

Cells. The head and neck squamous cell carcinoma cell lines (UT-SCCs) used in this study were obtained from Turku University Central Hospital, where these cell lines were established during surgery from primary or metastasized tumors (29). The cells were cultured at $37^{\circ} \mathrm{C}$ with $5 \% \mathrm{CO}_{2}$ in Dulbecco's modified Eagle's medium (DMEM) supplemented with $10 \%$ fetal bovine serum (FBS), 2 mM L-glutamine, non-essential amino acids and penicillin/streptomycin.

Adenoviral vectors. Both replicating viruses [Ad5/35-TERT, Ad5-TERT and Ad5 wild-type (wt)] and replication-deficient viruses (Ad5-lacZ) were used. Ad5/35-TERT and Ad5TERT are conditionally replicating viruses created by inserting the human telomerase reverse transcriptase promoter to regulate the expression of viral E1A. Ad5/35TERT also contains the hybrid Ad5/35 fiber gene in place of wt Ad5 fiber gene. The Ad5-lacZ virus has had its E1 region replaced with the Escherichia coli $\beta$-galactosidase gene (lacZ) under the control of RSV promoter. To generate the Ad5-lacZ virus, 293 HEK cells were cotransfected with shuttle plasmid pAd.RSV.LacZ and backbone plasmid pBHG10 as described previously (30). The CRADs Ad5-TERT and Ad5/35-TERT were prepared by cotransfecting 293 HEK cells with shuttle plasmid pXC1-TERTp-E1A (22) and backbone plasmid pBHG10 (for Ad5-TERT) or backbone plasmid pAd $\triangle \Psi F 35$ (for Ad5/35-TERT) (31). Viruses were propagated in 293 cells and harvested using freeze-thaw cycles. Extracted viruses were purified with double cesium gradient ultracentrifugation and plaque-forming units were determined using standard agarose-overlay plaque assay with 293 cells. The presence of correct modifications in
Ad5-TERT and Ad5/35-TERT virus genomes were verified by BstXI digestion (for hybrid fiber) and by PCR (both for hybrid fiber and hTERT promoter).

Flow cytometry. Adenoviral receptor expression levels were determined using FACS with receptor-specific monoclonal antibodies. Near confluent cells were released with trypsinization and diluted to $1 \times 10^{6}$ cells $/ \mathrm{ml}$ concentration in PBS containing $1 \% \mathrm{FBS}$ and $1 \%$ BSA. Next, $5 \times 10^{5}$ cells were incubated in the presence of primary antibody in $4^{\circ} \mathrm{C}$ for $30 \mathrm{~min}$ (anti-CAR, RmcB 1:100, Upstate Biotechnology, Lake Placid, NY; anti-CD46, E4.3 1:200, BD Pharmingen, San Diego, CA; anti- $\alpha_{v}$ integrin (L230) 1:100, conditioned medium collected from ATCC HB-8448 hybridoma cell line) or isotype control dilution (mouse IgG1 isotype control, 679.1Mc7 1:10, Immunotech, Marseille, France; mouse $\operatorname{IgG} 2 \mathrm{a}, \kappa$ isotype control, G155-178 1:200, BD Pharmingen). Cells were then washed twice with ice-cold PBS containing $1 \%$ FBS and BSA. Next, cells were incubated as before in the presence of a secondary antibody (FITC-conjugated goat anti-mouse IgG 1:100, Calbiochem, La Jolla, CA). Cells were washed again as described above and fixed to a final volume of $500 \mu \mathrm{l}$ of $4 \%$ paraformaldehyde. Samples were then analyzed by flow cytometry in the Turku Centre for Biotechnology Cell Imaging Core facility on a FACScan machine using CellQuest FACS analysis software (Becton Dickinson, Mountain View, CA).

MTT assay. For MTT assay, 5000 UT-SCC-7 or -10 cells were plated to 96-well plates and allowed to adhere overnight. Next morning the plated cells were infected with Ad5/35-TERT, Ad5-TERT, Ad5 wt or Ad5-lacZ using MOIs $0,5,10$ and $30 \mathrm{pfu} /$ cell for $2 \mathrm{~h}$ in serum-free medium at $37^{\circ} \mathrm{C}$ with $5 \% \mathrm{CO}_{2}$ after which the virus containing medium was replaced with normal medium. For MOI 0 infections, equal volume of PBS was added. All infections were done in triplicates. All virus and PBS dilutions were made in serumfree medium. MTT (15 $\mu \mathrm{l})$ coloring solution (Promega, USA) was added to the wells for color production by viable cells at $0,24,48$ and $72 \mathrm{~h}$ postinfection. The reaction was incubated for $4 \mathrm{~h}$ in $37^{\circ} \mathrm{C}$ with $5 \% \mathrm{CO}_{2}$. After incubation $100 \mu 1 \mathrm{MTT}$ stopping solution (Promega) was added to the wells and further incubated for $1 \mathrm{~h}$ after which absorbance was measured at $572 \mathrm{~nm}$ with Victor II (Perkin-Elmer, Finland).

Trypan blue exclusion assay. UT-SCC-7 or -10 HNSCC cells (500000) were plated in triplicate on 6-well plates and allowed to adhere overnight. Cells were next infected with Ad5/35-TERT, Ad5-TERT, Ad5 wt or Ad5-lacZ using MOI $30 \mathrm{pfu} / \mathrm{cell}$, or mock infected with PBS. All virus and PBS dilutions were made in serum-free medium. After $2 \mathrm{~h}$ infection medium was replaced with fresh complete medium. The wells were photographed at time points 24,48 and $56 \mathrm{~h}$ postinfection. Finally the cells were detached from the wells with $500 \mu 12.5 \%$ trypsin solution and scraping at $56 \mathrm{~h}$ postinfection. Trypsin was neutralized with $500 \mu 1$ of complete medium containing $10 \%$ FBS. Cell suspension was centrifuged for $4 \mathrm{~min}$ at $5000 \mathrm{rpm}$ to pellet the cells. Pelleted cells were resuspended in 300-1500 $\mu 1$ of serum-free medium depending on the amount of cells evaluated by the investigator. To stain the viable cells a 1:1 dilution was prepared in trypan blue 
Table I. Clinical characteristics and adenoviral receptor expression levels of UT-SCC cells.

\begin{tabular}{|c|c|c|c|c|c|c|c|}
\hline \multirow[b]{2}{*}{ Cell line } & \multirow{2}{*}{$\begin{array}{l}\text { Primary tumor } \\
\text { location }\end{array}$} & \multirow{2}{*}{$\begin{array}{c}\text { Histological } \\
\text { grade }^{\mathrm{a}}\end{array}$} & \multirow{2}{*}{$\begin{array}{c}\text { TNM } \\
\text { diagnosis }\end{array}$} & \multirow{2}{*}{$\begin{array}{l}\text { Survival } \\
\text { in months }\end{array}$} & \multicolumn{3}{|c|}{ Receptor levels (\%) } \\
\hline & & & & & CAR & $\alpha_{\mathrm{v}}$ & CD46 \\
\hline UT-SCC-7 & Temporal skin & $>50 \%$ & T1N0M0 & 35 & 55.2 & 91.3 & 90.0 \\
\hline UT-SCC-10 & Tongue & $>50 \%$ & T1N0M0 & 13 & 3.2 & 76.6 & 94.0 \\
\hline
\end{tabular}

${ }^{\mathrm{a} C e l l s ~}(>50 \%)$ are differentiated as evaluated by pathologist during surgery.
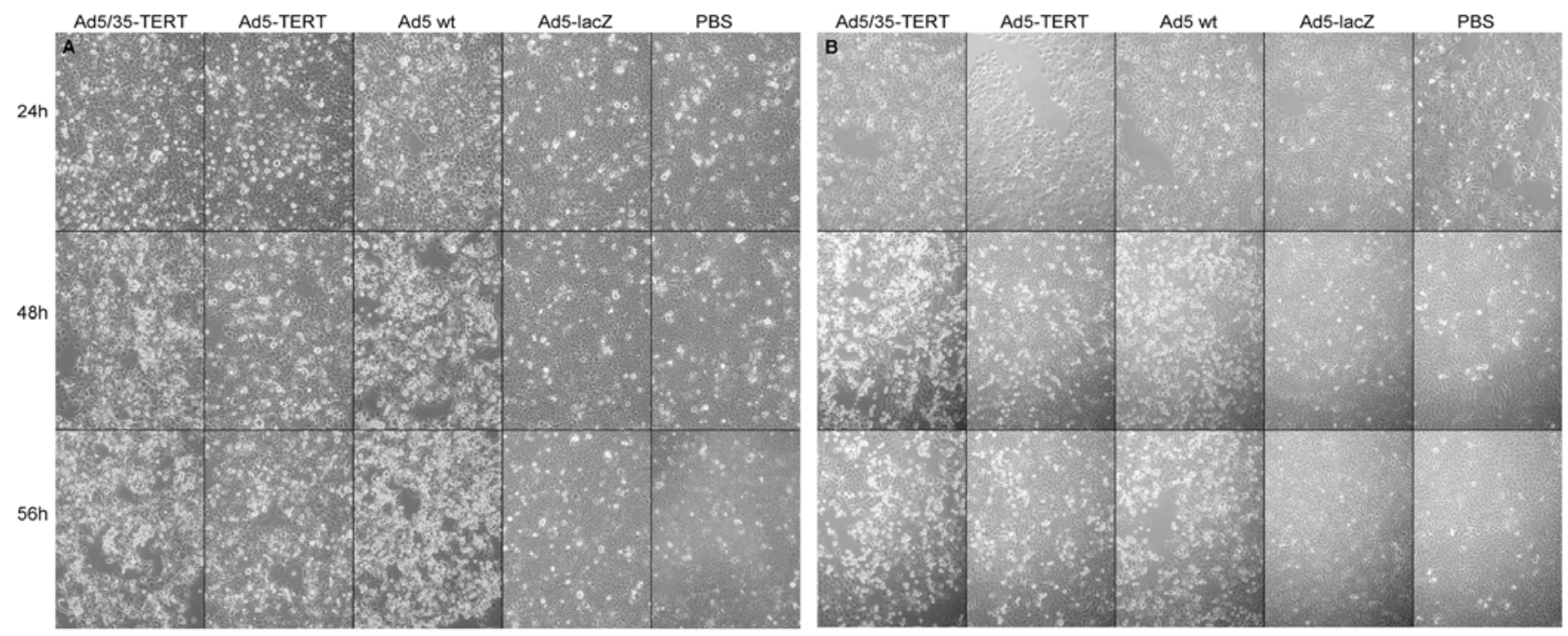

Figure 1. Cytopathic effects of Ad5/35-TERT and Ad5-TERT in UT-SCC-7 (A) and -10 (B) cell lines. Cells were infected with Ad5/35-TERT, Ad5-TERT, Ad5-lacZ and PBS (mock) with MOI $30 \mathrm{pfu} /$ cell. After $2 \mathrm{~h}$ the virus containing medium was removed and fresh medium was added. Cells were photographed at 24,48 and $56 \mathrm{~h}$ postinfection.

working solution. Viable and non-viable cells were counted separately in a Bürker chamber cytometer.

HNSCC in vivo mouse model. To evaluate the effects of Ad5/35-TERT and Ad5-TERT on tumor growth in in vivo, we used an in vivo animal model where pretreated primary tumor cells are injected into the flanks of SCID mice. In two separate experiments UT-SCC-7 and -10 primary tumor cells were infected either with Ad5/35-TERT or Ad5-TERT or mock infected with PBS using MOI $30 \mathrm{pfu} / \mathrm{cell}$ in serum-free medium. After $2 \mathrm{~h}$ infection cells were trypsinized, centrifuged for $4 \mathrm{~min} 5000 \mathrm{rpm}$ and resuspended in cold PBS 5x10 cells $/ 100 \mu 1$. The treated cells were injected into the flanks of SCID mice in $100 \mu 1$ volume. UT-SCC-7 cells were injected into SCID/SCID mice in two groups: Ad5/35-TERT $(n=4)$ and Ad5-TERT $(n=4)$. UT-SCC-10 cells were injected into NOD/SCID mice in two groups: Ad5/35-TERT $(n=10)$ and Ad5-TERT $(n=10)$. In both experiments tumor growth was observed 3 times a week for 8 weeks with UT-SCC-7 cells and for 3 weeks with UT-SCC-10 cells. The tumor volume was measured with microcalibers by measuring the long axis and the short axis. Tumor volume was calculated using the following formula: (tumor volume; $\mathrm{mm}^{3}$ ) $=$ (long axis; $\mathrm{mm}$ ) $\mathrm{x}(\text { short axis; } \mathrm{mm})^{2} \mathrm{x}(\pi / 6)$. Mice were sacrificed using $\mathrm{CO}_{2}$.
All animal work was done by trained scientists with permission from the Finnish laboratory animal board.

Statistical analysis and data presentation. For in vitro studies, data are presented as mean viable cell count $( \pm$ SD) after treatments. For in vivo tumor development studies, data are presented as mean tumor volume $( \pm$ SEM) over time. Statistical analysis was performed using t-test analysis. Differences with $\mathrm{p}<0.05$ were considered statistically significant.

\section{Results}

Adenoviral receptor expression. In this study we sought to determine the effect of Ad5/35-based transductional targeting on the anti-tumor efficacy of a conditionally replicating adenovirus. We utilized two HNSCC cell lines (UT-SCCs) established from primary tumors of head and neck cancer patients at the time of operation. The cell lines exhibit highly different CAR expression levels but similar growth characteristics. Full clinical and histopathological data are available on these cells (Table I). Flow cytometry was used to determine the expression levels of CAR, CD46 and $\alpha_{\mathrm{v}}$ integrins for the UT-SCC cell lines 7 and 10 used in this study (Table I). CD46 was expressed at high levels by both cell lines, whereas CAR 

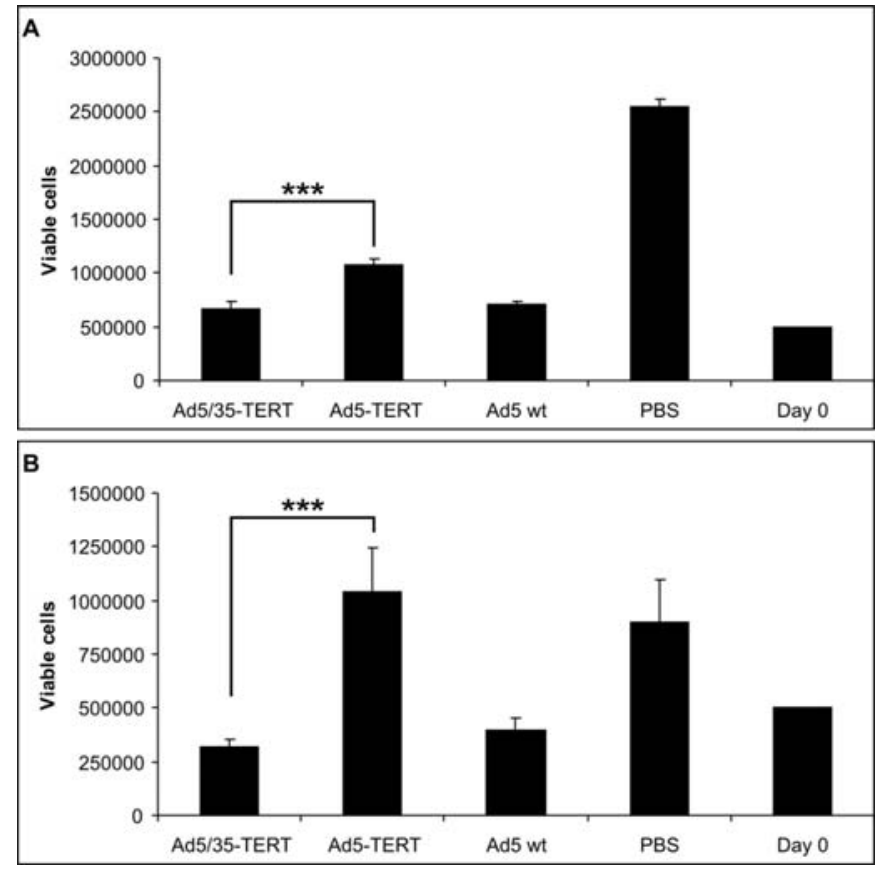

Figure 2. MOI 30 cytotoxicity assay of Ad5/35-TERT and Ad5-TERT. UTSCC-7 (A) and -10 (B) cells (500000 each) were infected with MOI 30 $\mathrm{pfu} / \mathrm{cell}$ for $2 \mathrm{~h}$ after which the virus medium was replaced with fresh medium. Live cells were counted $56 \mathrm{~h}$ postinfection. All experiments were done in triplicates. Statistical significance between Ad5/35-TERT and Ad5-TERT is indicated $\left({ }^{*} \mathrm{p}<0.05,{ }^{* *} \mathrm{p}<0.01,{ }^{* * *} \mathrm{p}<0.005 ; \mathrm{N} / \mathrm{S}\right.$, no statistical significance).

expression was higher in UT-SCC-7 (55.2\%) and low in UTSCC-10 cell line $(3.2 \%)$. Expression of $\alpha_{v}$ integrin was high in both cell lines (17).

Cytotoxicity of Ad5-TERT and Ad5/35-TERT in vitro. UTSCC-7 and UT-SCC-10 cell lines were infected with MOI $30 \mathrm{pfu} / \mathrm{cell}$ (MOI 30 assay). We also included wild-type (wt) Ad5, non-replicative Ad5-lacZ and PBS mock infection in the experiments as controls. Infected cells were photographed at time points 24, 48 and $56 \mathrm{~h}$ postinfection (Fig. 1). Infection with both CRADs as well as wt virus resulted in clear cytopathic effect (CPE) in both high-CAR (UT-SCC-7) and lowCAR (UT-SCC-10) cells already at $48 \mathrm{~h}$. There was no visible difference in $\mathrm{CPE}$ produced by the two CRADs in high-CAR expressing UT-SCC-7 cells. However, in UT-SCC-10 cells with low CAR expression, Ad5/35-TERT was clearly more effective than Ad5-TERT (Fig. 1).

The cytotoxic differences of Ad5-TERT and Ad5/35TERT were also evaluated by directly counting live cells $56 \mathrm{~h}$ after infection with MOI 30 pfu/cell (Fig. 2). Analysis of viable cells showed that the Ad5/35-TERT was 1.6 times more efficient in killing UT-SCC-7 cells and 3.25 times more efficient in killing UT-SCC-10 cells than Ad5-TERT. In this experiment, the difference was statistically significant in both cell lines, $\mathrm{p}=0.0008$ for UT-SCC-7 and $\mathrm{p}=0.0021$ for UT-SCC-10 cell line. Furthermore, Ad5/35-TERT was able to reduce the cell count well below the initial number in UTSCC-10 cell line, but not in UT-SCC-7 cell line.

We also employed standard MTT assay (32) to evaluate in detail the differences in cytotoxic effects of the CRADs
(Fig. 3). The results essentially corroborated the findings from the MOI 30 assay. Cells were infected with MOIs 5, 10 and 30 and cytotoxic effect was measured at $0,24,48$ and $72 \mathrm{~h}$ postinfection. In UT-SCC-7 cell line with high CAR expression Ad5/35-TERT was somewhat more effective than Ad5-TERT, with statistically significantly improved cytotoxicity at MOIs 10 and 30 . In these cells the wild-type virus was slightly more effective than either of the CRADs. In the UT-SCC-10 cell line with low CAR expression the results were clearly different. The difference between the two CRADs was clearly more profound, with Ad5/35-TERT being statistically significantly more effective with all MOIs. Ad5-TERT was able to induce cytotoxicity above background levels only with the highest MOI and Ad5/35-TERT at MOI 5 was more effective in reducing cell growth than Ad5-TERT at MOI 30 ( $\mathrm{p}=0.016)$. In these cells the slightly more effective replication of the wild-type virus was countered with the effective cell entry of the Ad5/35-TERT, making it statistically significantly more effective with all MOIs.

Anti-tumor efficacy of Ad5-TERT and Ad5/35-TERT in a mouse model. The ability of CRADs Ad5-TERT and Ad5/35TERT to affect tumor growth was studied in a mouse model (Fig. 4). UT-SCC-7 or -10 cells were infected with Ad5-TERT or Ad5/35-TERT using MOI $30 \mathrm{pfu} / \mathrm{cell}$. Infected cells were injected subcutaneously into the flanks of immunodeficient mice. With the UT-SCC-7 cell line tumor volume grows steadily over time in mice that received Ad5-TERT treated cells whereas Ad5/35-TERT group mice developed only small grain sized tumors at best. With UT-SCC-7 cells tumor growth in Ad5-TERT group reached $23 \pm 3.6 \mathrm{~mm}^{3}$ in average 29 days postinjection, whereas tumors in Ad5/35-TERT group reached average size of only $4.5 \pm 2.1 \mathrm{~mm}^{3}$ in 29 days postinjection, demonstrating that Ad5/35-TERT inhibited tumor development more efficiently than Ad5-TERT ( $\mathrm{p}=0.028$ ). Experiments with UT-SCC-10 cell line showed similar results. At day 6 postinjection the average tumor sizes in groups Ad5-TERT and Ad5/35-TERT were $70.2 \pm 3.8$ and $15.4 \pm 1.3 \mathrm{~mm}^{3}$, respectively ( $\mathrm{p}=0.0002$ ). Tumor volumes were decreased to $6.4 \pm 0.6$ (for Ad5-TERT) and 2.4 $\pm 0.3 \mathrm{~mm}^{3}$ (for Ad5/35-TERT) $(\mathrm{p}=0.035)$ at day 15 and by 20 days postinjection Ad5-TERT group tumors had maintained this size and Ad5/35-TERT group tumors had disappeared with only grain sized residual tumors in some of the mice.

\section{Discussion}

In this study, we wanted to address two key questions related to CRAD-based tumor therapy. First, what is the added benefit of using retargeted viruses with enhanced cellular entry to the cytotoxicity of CRADs. Second, what is the effect of target cell CAR expression on the efficacy of CRADs. To this end we chose two primary HNSCC cell lines with high and low CAR expression reflecting the high variability of CAR expression in primary tumors and tested the efficacy of a non-targeted (Ad5-TERT) and targeted (Ad5/35-TERT) CRADs on these cells.

Several factors make head and neck squamous cell carcinoma one of the most promising targets for cancer gene therapy. Most HNSCC are localized to the oral pharynx 

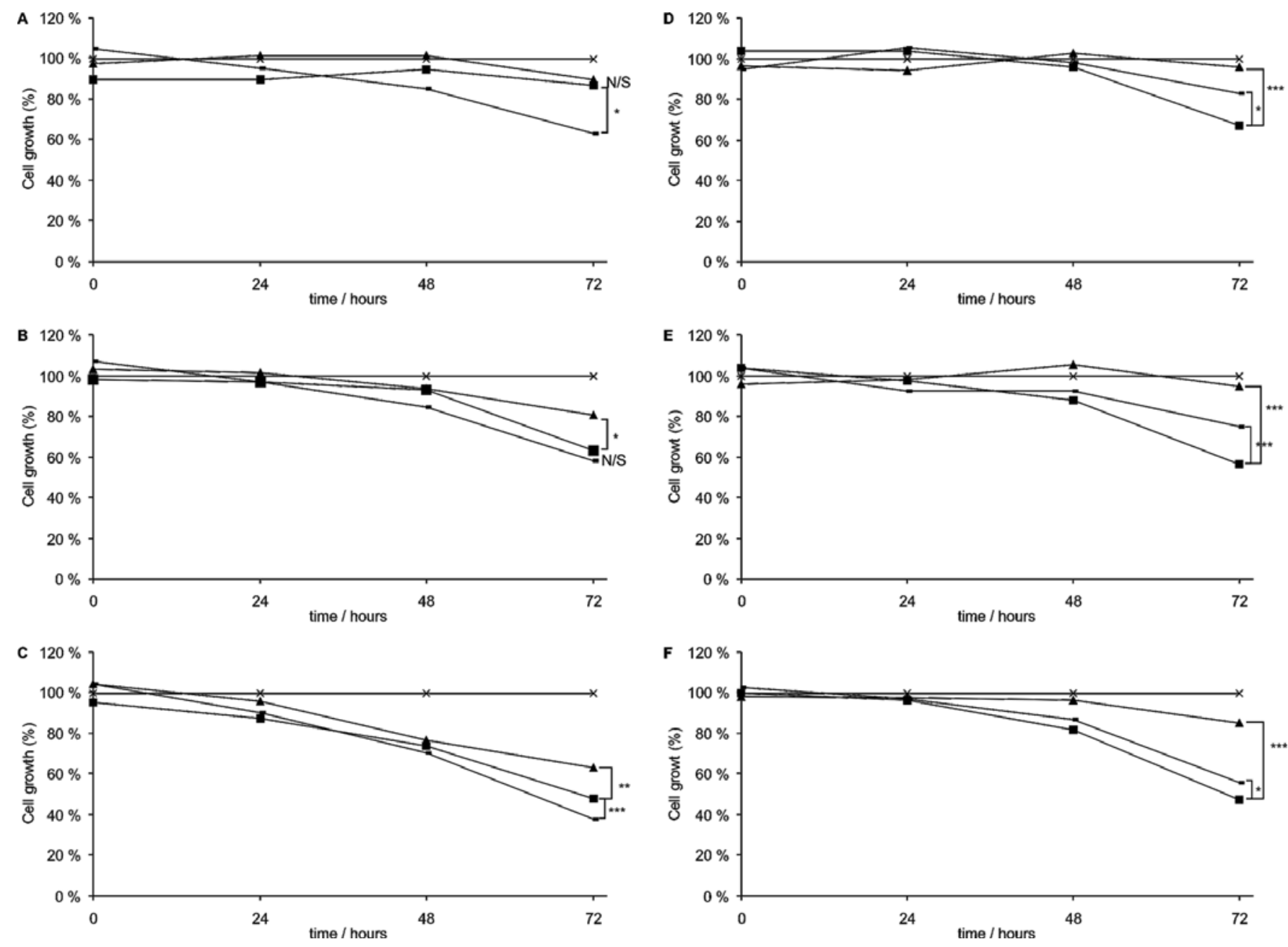

Figure 3. MTT assay of Ad5/35-TERT and Ad5-TERT. UT-SCC-7 (A-C) and UT-SCC-10 (D-F) cells (5000 each) were infected with MOIs 5 (A and D), 10 (B and $\mathrm{E}$ ) or 30 (C and F) pfu/cell with viruses Ad5/35-TERT (solid box), Ad5-TERT (solid triangle), Ad5 wt (minus sign) or mock infected with PBS (X) for $2 \mathrm{~h}$ after which the virus medium was replaced with fresh medium. Color reaction was initiated at time points $0,24,48$ and $72 \mathrm{~h}$ postinfection and color formation was measured spectrophotometrically at $572 \mathrm{~nm}$. All experiments were done in triplicates. Statistical significance comparing Ad5/35-TERT to Ad5-TERT or Ad5 wt is indicated $\left({ }^{*} \mathrm{p}<0.05,{ }^{* *} \mathrm{p}<0.01{ }^{* * *} \mathrm{p}<0.005 ; \mathrm{N} / \mathrm{S}\right.$, no statistical significance).

cavity, making the tumors relatively easily accessible to direct intratumoral injection of the gene therapy vector. In addition, metastases of the tumor seem to be a late-stage occurrence and therefore early loco-regional control of the disease is paramount (33). We have previously shown that HNSCC cells express primary Ad5 receptor CAR at decreased and highly variable levels leading to inefficient transduction of these cells with Ad5 vectors and demonstrated that this problem can be circumvented using an Ad5/35 hybrid virus (17).

In vitro experiments demonstrated a statistically significant difference in cytotoxicity in favor of the transductionally targeted CRAD (Figs. 2 and 3). However, this difference was relatively small in HNSCC cells with high CAR expression level. In these cells the wild-type virus was also slightly more effective than the targeted Ad5/35-TERT virus. In contrast, in HNSCC cells with low CAR expression the targeted virus Ad5/35-TERT was clearly more effective than the non-targeted Ad5-TERT or the wild-type virus. These results indicate that effective cell entry plays a key role in the efficacy of CRADs. In addition, the results indicate that the added advantage of
CRAD targeting depends on the level of CAR expression on tumor cells. Other factors also play a role, such as heparan sulfates, which are expressed by various tumors and have also been shown to be used by adenoviruses as secondary receptors for cell attachment and entry (34).

The in vivo mouse model experiments demonstrated that the hybrid CRAD Ad5/35-TERT was more effective than Ad5-TERT in inhibiting tumor growth in both UT-SCC cells (Fig. 4). In preliminary experiments the primary HNSCC cells UT-SCC-7 and UT-SCC-10 exhibited different growth characteristics when grown subcutaneously in vivo. We observed that UT-SCC-7 cells grow slowly in vivo, but in the end develop solid tumors whereas UT-SCC-10 cells grow more rapidly in vivo, but tumor development is only transient in all groups.

Several approaches have been utilized to target adenoviruses in order to improve efficacy and decrease toxicity. Determining the most effective targeting strategy is difficult and presently there is an incomplete understanding of the mechanisms that determine adenovirus biodistribution, especially after systemic administration. Nevertheless, the 

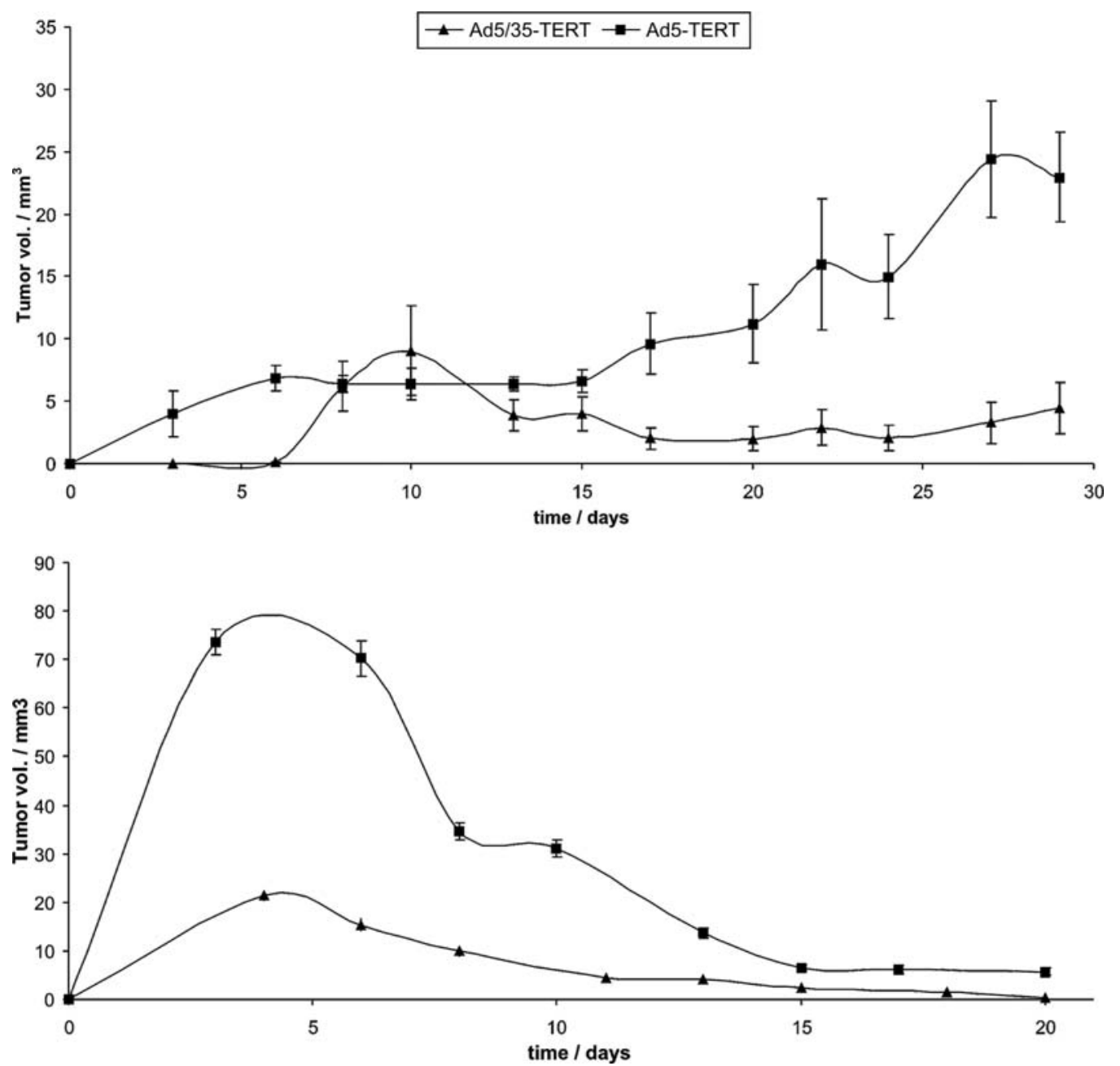

Figure 4. Tumor growth in an in vivo mouse model. UT-SCC-7 and -10 cells were infected with Ad5/35-TERT, Ad5-TERT at MOI $30 \mathrm{pfu} / \mathrm{cell}$ for $2 \mathrm{~h}$ after which $5 \times 10^{6}$ infected cells in $100 \mu 1$ volume PBS were injected onto the flanks of immunodeficient mice. Tumor sizes were measured 3 times a week. Error bars: mean + SEM ( $\mathrm{n}=4$ for UT-SCC-7, $\mathrm{n}=10$ for UT-SCC-10).

Ad5/35 hybrid virus targeting strategy has been shown to be effective in circumventing toxic side effects related to adenoviral gene transfer. Sova et al (15) have shown earlier that the hybrid Ad5/35 is less hepatotoxic in CD46 transgenic mice after intravenous administration than Ad5 virus. Systemic administration of Ad5/35 vectors to baboons, which express CD46 in a similar pattern to humans, did not cause tissue damage while administration of Ad5 vectors resulted in inflammation and damage to the endothelium (35). These studies suggest that hybrid Ad5/35 could also be less toxic in humans. Recently, the efficacy of two CRADs targeted either by using fiber-swapping technology or by engineering the RGD-targeting motif to the fiber gene was compared (36). The fiber-swapped virus Ad5-CXCR4-F5/3 was significantly more effective in infecting and killing ovarian cancer cells than RGD-targeted Ad5-CXCR4-RGD, suggesting that in addition to increased safety, fiber-swapping technology may be the most efficient targeting strategy for improving therapeutic efficacy as well.

Telomerase activity has been reported to be reactivated in various cancers (including HNSCC), which warrants the use of this transcriptional regulation system and several previous studies have demonstrated the effectiveness of hTERT driven
CRADs in various cancer models $(23,24,37)$. In this study, we used the hTERT promoter to evaluate the roles of retargeting and CAR-expression levels in the anti-tumor efficacy of CRADs. The telomerase promoter employed here has previously been demonstrated to be effective in a hepatocellular carcinoma model (22). However, telomerase promoter constructs with improved specificity have subsequently been constructed (38). These 2 nd generation constructs should be combined with future targeted CRADs.

The improved therapeutic efficacy caused by retargeting of CRADs supports the development of this concept for clinical trials for head and neck cancer. Our results also indicate that adenoviral receptor expression is a major determinant in the success of CRAD therapy and suggest that in future clinical trials adenoviral receptor expression levels should be analyzed from tumor samples prior to administration of gene therapy.

\section{Acknowledgements}

We thank Marjo Hakkarainen and Susanna Pyökäri (Turku Centre for Biotechnology) for their expertise on cell culture and viral vectors and Seija Lindqvist (University of Turku 
Central Animal Laboratory) for animal care. This study was supported by the Academy of Finland, Finnish Medical Foundation, Turku University Central Hospital, Turku University Foundation, Cancer Foundation of South-Western Finland and Turku Graduate School of Biomedical Sciences.

\section{References}

1. Bergelson JM, Cunningham JA, Droguett G, et al: Isolation of a common receptor for Coxsackie B viruses and adenoviruses 2 and 5. Science 275: 1320-1323, 1997.

2. Tomko RP, Xu R and Philipson L: HCAR and MCAR: the human and mouse cellular receptors for subgroup $\mathrm{C}$ adenoviruses and group B coxsackieviruses. Proc Natl Acad Sci USA 94: 3352-3356, 1997.

3. Roelvink PW, Lizonova A, Lee JG, et al: The coxsackievirusadenovirus receptor protein can function as a cellular attachment protein for adenovirus serotypes from subgroups A, C, D, E and F. J Virol 72: 7909-7915, 1998.

4. Wickham TJ, Mathias P, Cheresh DA and Nemerow GR: Integrins alpha $\mathrm{v}$ beta 3 and alpha $\mathrm{v}$ beta 5 promote adenovirus internalization but not virus attachment. Cell 73: 309-319, 1993.

5. Li D, Duan L, Freimuth P and O'Malley BW Jr: Variability of adenovirus receptor density influences gene transfer efficiency and therapeutic response in head and neck cancer. Clin Cancer Res 5: 4175-4181, 1999 .

6. Hemmi S, Geertsen R, Mezzacasa A, Peter I and Dummer R: The presence of human coxsackievirus and adenovirus receptor is associated with efficient adenovirus-mediated transgene expression in human melanoma cell cultures. Hum Gene Ther 9: 2363-2373, 1998.

7. Wickham TJ, Segal DM, Roelvink PW, Carrion ME, Lizonova A, Lee GM and Kovesdi I: Targeted adenovirus gene transfer to endothelial and smooth muscle cells by using bispecific antibodies. J Virol 70: 6831-6838, 1996.

8. Nettelbeck DM, Miller DW, Jerome V, et al: Targeting of adenovirus to endothelial cells by a bispecific single-chain diabody directed against the adenovirus fiber knob domain and human endoglin (CD105). Mol Ther 3: 882-891, 2001.

9. Kasono K, Blackwell JL, Douglas JT, et al: Selective gene delivery to head and neck cancer cells via an integrin targeted adenoviral vector. Clin Cancer Res 5: 2571-2579, 1999.

10. Einfeld DA, Schroeder R, Roelvink PW, Lizonova A, King CR, Kovesdi I and Wickham TJ: Reducing the native tropism of adenovirus vectors requires removal of both CAR and integrin interactions. J Virol 75: 11284-11291, 2001

11. Gaggar A, Shayakhmetov DM and Lieber A: CD46 is a cellular receptor for group B adenoviruses. Nat Med 9: 1408-1412, 2003.

12. Seya T, Hirano A, Matsumoto M, Nomura M and Ueda S: Human membrane cofactor protein (MCP, CD46): multiple isoforms and functions. Int J Biochem Cell Biol 31: 1255-1260, 1999.

13. Shayakhmetov DM, Li ZY, Ni S and Lieber A: Targeting of adenovirus vectors to tumor cells does not enable efficient transduction of breast cancer metastases. Cancer Res 62: 1063-1068, 2002

14. Segerman A, Mei YF and Wadell G: Adenovirus types 11p and $35 \mathrm{p}$ show high binding efficiencies for committed hematopoietic cell lines and are infective to these cell lines. J Virol 74: 1457-1467, 2000.

15. Sova P, Ren XW, Ni S, Bernt KM, Mi J, Kiviat N and Lieber A: A tumor-targeted and conditionally replicating oncolytic adenovirus vector expressing TRAIL for treatment of liver metastases. Mol Ther 9: 496-509, 2004.

16. Shinozaki K, Suominen E, Carrick F, et al: Efficient infection of tumor endothelial cells by a capsid-modified adenovirus. Gene Ther 13: 52-59, 2006.

17. Suominen E, Toivonen R, Grenman R and Savontaus M: Head and neck cancer cells are efficiently infected by Ad5/35 hybrid virus. J Gene Med 8: 1223-1231, 2006.
18. Haviv YS and Curiel DT: Engineering regulatory elements for conditionally-replicative adeno-viruses. Curr Gene Ther 3: 357-385, 2003

19. Ito H, Kyo S, Kanaya T, Takakura M, Koshida K, Namiki M and Inoue $\mathrm{M}$ : Detection of human telomerase reverse transcriptase messenger RNA in voided urine samples as a useful diagnostic tool for bladder cancer. Clin Cancer Res 4: 2807-2810, 1998.

20. Takakura M, Kyo S, Kanaya T, Hirano H, Takeda J, Yutsudo M and Inoue M: Cloning of human telomerase catalytic subunit (hTERT) gene promoter and identification of proximal core promoter sequences essential for transcriptional activation in immortalized and cancer cells. Cancer Res 59: 551-557, 1999.

21. Shay JW, Zou Y, Hiyama E and Wright WE: Telomerase and cancer. Hum Mol Genet 10: 677-685, 2001.

22. Huang TG, Savontaus MJ, Shinozaki K, Sauter BV and Woo SL: Telomerase-dependent oncolytic adenovirus for cancer treatment. Gene Ther 10: 1241-1247, 2003.

23. Kawashima T, Kagawa S, Kobayashi N, et al: Telomerasespecific replication-selective virotherapy for human cancer. Clin Cancer Res 10: 285-292, 2004.

24. Kim E, Kim JH, Shin HY, et al: Ad-mTERT-delta19, a conditional replication-competent adenovirus driven by the human telomerase promoter, selectively replicates in and elicits cytopathic effect in a cancer cell-specific manner. Hum Gene Ther 14: 1415-1428, 2003.

25. Zou W, Luo C, Zhang Z, et al: A novel oncolytic adenovirus targeting to telomerase activity in tumor cells with potent. Oncogene 23: 457-464, 2004.

26. Parkin DM, Bray F, Ferlay J and Pisani P: Global cancer statistics, 2002. CA Cancer J Clin 55: 74-108, 2005.

27. Fuller CD, Wang SJ, Thomas CR Jr, Hoffman HT, Weber RS and Rosenthal DI: Conditional survival in head and neck squamous cell carcinoma: results from the SEER dataset 1973-1998. Cancer 109: 1331-1343, 2007.

28. Khuri FR, Nemunaitis J, Ganly I, et al: a controlled trial of intratumoral ONYX-015, a selectively-replicating adenovirus, in combination with cisplatin and 5-fluorouracil in patients with recurrent head and neck cancer. Nat Med 6: 879-885, 2000.

29. Grenman SE, Van Dyke DL, Worsham MJ, et al: Phenotypic characterization, karyotype analysis and in vitro tamoxifen sensitivity of new ER-negative vulvar carcinoma cell lines, UMSCV-1A and UM-SCV-1B. Int J Cancer 45: 920-927, 1990.

30. Bautista DS, Hitt M, McGrory J and Graham FL: Isolation and characterization of insertion mutants in E1A of adenovirus type 5. Virology 182: 578-596, 1991.

31. Shayakhmetov DM, Papayannopoulou T, Stamatoyannopoulos G and Lieber A: Efficient gene transfer into human CD34(+) cells by a retargeted adenovirus vector. J Virol 74: 2567-2583, 2000.

32. Mosmann T: Rapid colorimetric assay for cellular growth and survival: application to proliferation and cytotoxicity assays. J Immunol Methods 65: 55-63, 1983.

33. Goebel EA, Davidson BL, Zabner J, Graham SM and Kern JA: Adenovirus-mediated gene therapy for head and neck squamous cell carcinomas. Ann Otol Rhinol Laryngol 105: 562-567, 1996.

34. Dechecchi MC, Melotti P, Bonizzato A, Santacatterina M, Chilosi M and Cabrini G: Heparan sulfate glycosaminoglycans are receptors sufficient to mediate the initial binding of adenovirus types 2 and 5. J Virol 75: 8772-8780, 2001

35. Ni S, Bernt K, Gaggar A, Li ZY, Kiem HP and Lieber A: Evaluation of biodistribution and safety of adenovirus vectors containing group B fibers after intravenous injection into baboons. Hum. Gene Ther 16: 664-677, 2005.

36. Rocconi RP, Zhu ZB, Stoff-Khalili M, et al: Treatment of ovarian cancer with a novel dual targeted conditionally replicative adenovirus (CRAd). Gynecol Oncol 105: 113-121, 2007.

37. Irving J, Wang Z, Powell S, et al: Conditionally replicative adenovirus driven by the human telomerase promoter provides broad-spectrum antitumor activity without liver toxicity. Cancer Gene Ther 11: 174-185, 2004.

38. Bilsland AE, Merron A, Vassaux G and Keith WN: Modulation of telomerase promoter tumor selectivity in the context of oncolytic adenoviruses. Cancer Res 67: 1299-1307, 2007. 